\title{
Method verification study for nucleic acid test system
}

\author{
Libo Zhang, Chengping Ma, Rongrong Pang, Yuan Ke, Min Huang, Wenping Han, Xiaojun Lu* \\ Nanjing Red Cross Blood Center, Nanjing 210003, Jiangsu, China
}

\begin{abstract}
To identify a suitable method for nucleic acid test(NAT) system verification, several methods were used to verify the system's key parameters, such as the lowest limit of detection, specificity, accuracy and anti-interference ability. The lowest limit of detection for Grifols' Procleix Tigris System were HBV DNA 3.1 U/mL, HCV RNA $5.0 \mathrm{U} / \mathrm{mL}$, HIV RNA $21.2 \mathrm{U} / \mathrm{mL}$; accuracy 100\%; anti-interference lipemia (triglyceride) $<33.23 \mathrm{mmol} / \mathrm{L}$, hemolysis (hemoglobin concentration) $<5 \mathrm{~g} / \mathrm{L}$. There were no significant differences between the claimed specification of both the Grifols' Procleix Tigris Systems and reagents, which both met with published test requirements. New equipment installation or regular verification are necessary to ensure the reliable operation of equipment, which ensure the quality of analysis and test. A systematic method was practiced in our laboratory, which was able to confirm that commercial NAT reagents meet the rigorous standards of blood screening. This study provides a very useful model for other blood screening laboratories and NAT kits.
\end{abstract}

Keywords: nucleic acid, verification, lowest limit of detection, specificity, accuracy, anti-interference

\section{INTRODUCTION}

Equipment system performance verification aims to confirm that the basic performance of the testing system meets clinical requirements ${ }^{[1-3]}$. In this way, researchers are able to verify literature results or the data provided by the manufacturer ${ }^{[4,5]}$. Only by passing the verification, the testing system can be used for day-today testing ${ }^{[6]}$. Two files, Guidance for Blood Center Technical Operations, and Guidance on the Application of Accreditation Criteria for the Medical Laboratory Quality and Competence in the Field of Molecular Diagnostics both required system verification. Until now, there has been no unified standard method for nucleic acid test(NAT) system performance verification. For this report, our laboratory used several methods to verify, compare and comprehensively evaluate the lowest detecting limit, specificity, accu- racy and anti-interference ability of each test system to find the most appropriate verification method. The results outlined are intended to stand as a reference for future NAT system performance verification.

\section{MATERIALS AND METHODS}

\section{Plasma samples}

Samples were collected using vacuum blood collector tubes with gel anticoagulants from the volunteers, at $4 \sim 5 \mathrm{~mL}$ each. They were centrifuged at $1,200 \mathrm{~g}$ for $20 \mathrm{~min}$, and tested negative for HBV DNA, HCV RNA and HIV RNA using the NAT system.

\section{Standard references and serum plate standard}

The reference standards of HBV DNA, HCV RNA

*Correspondence to: Xiaojun Lu, Nanjing Red Cross Blood Center, Nanjing 210003, Jiangsu, China. Tel: 0086-25-83471658. E-mail: 15345189821@189.cn.

Conflict of interests: The authors declared no conflict of interests. 
and HIV RNA are measured at concentrations of 50 and $500 \mathrm{U} / \mathrm{mL}, 50$ and $2,000 \mathrm{U} / \mathrm{mL}, 200$ and 2,000 U/ $\mathrm{mL}$ respectively, which were obtained from Conchstein Biology. Both specificity and accuracy verification used serum plates with 52 samples (Table 1). The lowest detection limit (analytical sensitivity) for verification was conducted with 180 samples, which were composed of HBV DNA, HCV RNA and HIV RNA detection limits (20 samples each) of 50\%, 95\%, and 100\%, respectively (Table 2).

Table 1 Sample summary for specificity and accuracy verification

\begin{tabular}{|c|c|c|c|c|c|}
\hline Number & Project & Content $(\mathrm{U} / \mathrm{mL})$ & Number & Project & Content $(\mathrm{U} / \mathrm{mL})$ \\
\hline 1 & HIV RNA & 6,000 & 27 & HBV DNA & 30 \\
\hline 2 & HCV RNA & 30 & 28 & NHP & N/A \\
\hline 3 & HBV DNA & 30 & 29 & HCV RNA & 300 \\
\hline 4 & NHP & N/A & 30 & HIVRNA & 30 \\
\hline 5 & HCV RNA & 3,000 & 31 & HBV DNA & 30 \\
\hline 6 & HIV RNA & 30 & 32 & NHP & N/A \\
\hline 8 & NHP & N/A & 34 & HIV RNA & 30 \\
\hline 9 & HBV DNA & 10,000 & 35 & HCV RNA & 30 \\
\hline 10 & HIV RNA & 30 & 36 & NHP & N/A \\
\hline 11 & HCV RNA & 30 & 37 & HIV RNA & 600 \\
\hline 12 & NHP & N/A & 38 & NHP & N/A \\
\hline 13 & HIV RNA & 6,000 & 39 & NHP & N/A \\
\hline 14 & NHP & N/A & 40 & NHP & N/A \\
\hline 16 & NHP & N/A & 42 & NHP & N/A \\
\hline 17 & HCV RNA & 3,000 & 43 & NHP & N/A \\
\hline 18 & NHP & N/A & 44 & NHP & N/A \\
\hline 19 & NHP & N/A & 45 & HBV DNA & 1,000 \\
\hline 20 & NHP & N/A & 46 & NHP & N/A \\
\hline 21 & HBV DNA & 10,000 & 47 & NHP & N/A \\
\hline 22 & NHP & N/A & 48 & NHP & N/A \\
\hline 23 & NHP & N/A & 49 & HBV DNA & 10,000 \\
\hline 24 & NHP & N/A & 50 & NHP & N/A \\
\hline 25 & HIV RNA & 600 & 51 & NHP & N/A \\
\hline 26 & HCV RNA & 30 & 52 & NHP & N/A \\
\hline
\end{tabular}

NHP: Normal Human(pooled) Plasma;N/A: Not Applicable.

Table 2 Sample summary for lowest detection limit verification

$(\mathrm{U} / \mathrm{mL}, n=20)$

\begin{tabular}{cccc}
\hline Project & HBV DNA & HCV RNA & HIV RNA \\
\hline $50 \%$ detection limit & 1.0 & 1.5 & 5.0 \\
$95 \%$ detection limit & 4.0 & 6.0 & 25.0 \\
$100 \%$ detection limit & 12.0 & 20.0 & 70.0 \\
\hline
\end{tabular}

\section{Instruments and reagents}

Procleix TIGRIS System (Grifols, Spain), Ultrio Plus Assay(Grifols, Spain), serum standard panel(Beijing Controls \& Standards Co. Ltd., China).

\section{Verification with the lowest limit of detection of serum plate}

According to the joint inspection (single inspection) method, we included both the negative and positive control plus quality control samples, with 20 samples for each test (HBV DNA, HCV RNA and HIV RNA) at various concentrations. The detection rate strictly followed the multi-corresponding confidence interval. The analytical sensitivity of the reagent was set when the reactivity rate was $\geqslant 95 \%$, with no less than 20 effective results at each concentration.

\section{Validation of the lowest limit of detection through standard reference dilution method}

The standard reference samples of nucleic acid HBV DNA (50 U/mL), HCV RNA (50 U/mL), HIV RNA (200 U/mL) were obtained from Beijing Controls \& Standards Co., Ltd. Normal fresh plasma (HBV DNA, HCV RNA and HIV RNA all negative) was used as the dilution matrix. The standard references were diluted lower than the detection limit as stated for the instrument under validation. The tests were repeated 20 times for each sample, as shown in Table 3. To pass the validation, the instrument needed to pass $95 \%$ of the tests (at least 19 times out of 20 repeats) (Table 4).

\section{System was verified with serum plate for its specificity and accuracy}

The 52 samples in the serum plate were tested in the order listed in Table 1. The tests were carried out according to the routine method, including both negative and positive controls, with a total of $52+$ pool rea- 
Table 3 Summary for experiment setup

\begin{tabular}{llc}
\hline Items & & Detail Infomation \\
\hline Date & $2017 / 12 / 8$ & \\
Instrument & Procleix TIGRIS & \\
Reagent and lot number & Procleix TIGRIS ULTRIO Plus 171833631501190 \\
Expiry Date & $2019 / 1 / 15$ & HCV RNA \\
Reference Standard & HBV DNA & 201705001 \\
Lot number of standard substance & 201708007 & $2019 / 5 / 2$ \\
Reference standard expiry date & $2019 / 8 / 22$ & 50 \\
The original concentration of the reference standard(U/mL) & 50 & 201706002 \\
Final concentration after dilution(U/mL) & 3.125 & $2019 / 6 / 9$ \\
$95 \%$ stated detection limit(U/mL) & 3.4 & 200 \\
\hline
\end{tabular}

Table 4 Verification results of the lowest limit of detection using standard substance dilution method

\begin{tabular}{|c|c|c|c|}
\hline \multirow{2}{*}{ Line items } & \multicolumn{2}{|c|}{ Result } & \multirow{2}{*}{ Relevance ratio } \\
\hline & + & - & \\
\hline HBV DNA & 19 & 1 & $95 \%$ \\
\hline HCV RNA & 20 & 0 & $100 \%$ \\
\hline HIV RNA & 20 & 0 & $100 \%$ \\
\hline
\end{tabular}

gents. The obtained test results needed no further split test. The result of each pool were compared with those in Table 1, and the outputs were recorded in Table 5 with the corresponding formula to calculate various performance indexes. The accuracywas calculated as $(a+d) /(a+b+c+d)$, and the specificity was calculated as $d /(b+d)$.

\section{Accuracy and specificity were verified using external quality assessment}

The sample size $(n)$ was $>30$. The accuracy and specificity were accessed based on the comparison between test results $v s$. predicted results.

Verification of anti-interference abilities toward blood with hyperlipidemia and hemolysis

The nucleic acid standard references HBV DNA $(500 \mathrm{U} / \mathrm{mL}), \mathrm{HCV}$ RNA $(2,000 \mathrm{U} / \mathrm{mL})$ and HIV RNA $(2,000 \mathrm{U} / \mathrm{mL})$ from Beijing Controls \& Standards Co., Ltd. were selected. According to the instructed level of blood lipid, hemolysis, corresponding HBV DNA, HCV RNA, HIV RNA triple negative hyperlipidemic blood (triglyceride $33.23 \mathrm{mmol} / \mathrm{L}$ ), severe hemolysis (hemoglobin concentration $5 \mathrm{~g} / \mathrm{L}$ ) fresh plasma, and normal fresh plasma were used as gradient dilution matrix. The standard references were diluted for 10 and 100 times accordingly to be hyperlipidemic blood, hemolysis references for comparison.

\section{Statistical analysis}

SPSS 23.0 statistical software was used for data collection and statistical analysis.

\section{RESULTS}

The results of lowest limit of detection by using blood serum plate

The lowest limit of detection for HBV DNA, HCV RNA, and HIV RNA using serum standard panels were $80 \%, 100 \%$, and $100 \%$ under $50 \%$ detection limit, respectively; $100 \%, 100 \%$, and $100 \%$ under both $95 \%$ detection limit and $100 \%$ detection limit(Table 6).

Table 5 The model for accuracy and specificity test

\begin{tabular}{lccc}
\hline & Predict positive & Predict negative & Sum \\
\hline Tested positive & $\mathrm{a}$ & $\mathrm{b}$ & $\mathrm{a}+\mathrm{b}$ \\
Tested negative & $\mathrm{c}$ & $\mathrm{d}$ & $\mathrm{c}+\mathrm{d}$ \\
Sum & $\mathrm{a}+\mathrm{c}$ & $\mathrm{b}+\mathrm{d}$ & \\
\hline
\end{tabular}

Table 6 Thelowest limit of detection by using blood serum plate

Line items 50\%detection limit 95\%detection limit $100 \%$ detection limit

\begin{tabular}{lccc}
\hline HBV DNA & $80 \%$ & $100 \%$ & $100 \%$ \\
HCV RNA & $100 \%$ & $100 \%$ & $100 \%$ \\
HIV RNA & $100 \%$ & $100 \%$ & $100 \%$ \\
\hline
\end{tabular}

Results for specificity and accuracy verification with serum plate

The detection result match for the 52 samples was $100 \%$. Both the specificity and accuracy was $100 \%$.

\section{External quality assessment was used to ver- ify the accuracy and specificity}

The assessment was conducted 3 times, at 10 samples each. The scores were $100 \%$. The specificity and the accuracy were both $100 \%$.

\section{Verification results of anti-interference abilities toward hyperlipidemic blood and hemolysis}

Beside the third test result for the 1:100 dilution of HCV RNA, standard substance in normal plasma was found negative (the root analysis was identified as accidental error), the remaining samples were all detected, as shown in Table 7. 
Table 7 Verification results of anti-interference abilities toward hyperlipidemic blood and hemolysis

\begin{tabular}{|c|c|c|c|c|c|c|c|c|c|c|}
\hline & \multirow{2}{*}{ dilution } & \multicolumn{3}{|c|}{ HBV DNA (500 U/mL) } & \multicolumn{3}{|c|}{ HCV RNA(2,000 U/mL) } & \multicolumn{3}{|c|}{ HBV DNA (500 U/mL) } \\
\hline & & Result 1 & Result 2 & Result 3 & Result 1 & Result 2 & Result 3 & Result 1 & Result 2 & Result 3 \\
\hline \multirow[t]{2}{*}{ Normal plasma } & $1: 10$ & + & + & + & + & + & + & + & + & + \\
\hline & $1: 100$ & + & + & + & + & + & - & + & + & + \\
\hline \multirow{2}{*}{ Hemolytic plasma } & $1: 10$ & + & + & + & + & + & + & + & + & + \\
\hline & $1: 100$ & + & + & + & + & + & + & + & + & + \\
\hline \multirow{2}{*}{$\begin{array}{l}\text { Hyperlipidemic blood } \\
\text { plasma }\end{array}$} & $1: 10$ & + & + & + & + & + & + & + & + & + \\
\hline & $1: 100$ & + & + & + & + & + & + & + & + & + \\
\hline
\end{tabular}

\section{DISCUSSION}

For the validation of the lowest detection limit, ready-to-use serum plates have consistent and reliable results, which makes testing more convenient, albeit with higher costs. The standard substance dilution method is cheaper, but there may be potential accuracy issues associated with dilution. We recommend the use of traceable equipment for quantification after dilution and the conduction of standard dilution verification studies. For accuracy and specificity verification, it was recommended to adopt the method of external quality assessment. For the anti-interference test, it is also important to check for dilution accuracy.

We used several methods to verify some key parameters of the NAT system. The results showed that the lowest limits of detection of HBV DNA, HCV RNA and HIV RNA were $3.4 \mathrm{U} / \mathrm{mL} 5.4 \mathrm{U} / \mathrm{mL}$ and $21.2 \mathrm{U} / \mathrm{mL}$, respectively. Both the specificity and accuracy of the device were $100 \%$. The system had a degree of anti-interference abilities toward lipoidemia and hemolysis.

The imported NAT system doesn't require any external reagents and consumables. It is a closed system whereby all reagents and consumables are provided from the same vendor, who is able to verify and confirm the system. For closed systems, this research indicated that laboratories only need to verify the vendor claimed specs and performance in their laboratory and personalized setting ${ }^{[7,8]}$. However, for open systems, such as the blood type detection system, blood cells, antibody reagents, saline, and other reagents and consumables are not from the same manufacturer ${ }^{[9-11]}$. The systems' reaction parameters, anti-interference performance, and changes in reagentsall have impacts on the results. Here it is necessary to verify changes in each step. For example, to verify a new automated blood typing system, optimization of the ratio between plasma and dilutedred blood cells wasoften performed to the utmost, as lipemia is afrequent endogenous interference which can produce an unidentifiable result.

The purpose of performance verification is to verify whether the parameters of the testing equipment meet the stated specification. Only after verification, the results can be guaranteed ${ }^{[12]}$. This means the verification of new equipment installations, as wellas the regular verification of existing equipment are necessary to ensure reliable operation. A systematic method was practiced in our laboratory which confirmed that commercially available NAT reagents meet published blood screening standards, which could provide a useful model for other blood screening laboratories and NAT kits.

However, there were still some deficiencies of our work, for example, we did not compare the five sets of nucleic acid test devices in our laboratory. Also, additional indicators, such as precision, sensitivity, linear range, etc. can make verification more complete.

\section{References}

[1] Chen SB, He ZY, Chen QK, et al. Performance verification of Roche Cobas s201 nucleic acid test system in Dongguan Blood Center. Asia-Pacific Journal of Blood Types and Genes, 2018, 2(3):171-5.

[2] Ris M, Bozicevic S, Biljak VR, et al. Analytical verification and quality assessment of the Tosoh HLC-723GX HbAlc analyzer. Pract Lab Med, 2017, 7: 15-8.

[3] Choi SC, Kim BS, Lim H, et al. MTF performance verification of an athermalized large-aperture IR optical system for space environment. Appl Opt, 2016, 55(30): 8413-8.

[4] Chakravarthy SN, Ramanathan S, S S, et al. EP15A3 based precision and trueness verification of VITROS HbAlC immunoassay. Indian J Clin Biochem, 2019, 34(1): 89-94.

[5] Killeen AA, Long T, Souers R, et al. Verifying performance characteristics of quantitative analytical systems: calibration verification, linearity, and analytical measurement range. Arch Pathol Lab Med, 2014, 138(9): 1173-81.

[6] Bourner G, De la Salle B, George T, et al. ICSH guidelines for the verification and performance of automated cell counters for body fluids. Int J Lab Hematol, 2014, 36(6): 598-612.

[7] Cui M, Ju S, Shi Y, et al. Performance verification of the Iris iQ200 sprint automated urine microscopy analyzer in a hospital routine laboratory. Clin Lab, 2017, 63(10): 1607-12.

[8] Plesch W, Wolf T, Breitenbeck N, et al. Results of the performance verification of the CoaguChek XS system. 
Thromb Res, 2008, 123(2): 381-9.

[9] Boccoz SA, Le Goff GC, Mandon CA, et al. Development and validation of a fully automated platform for extended blood group genotyping. J Mol Diagn, 2016, 18(1): 144-52.

[10] Gong T, Hong Y, Wang N, et al. Validation of a blood group genotyping method based on high-resolution melting curve analysis. Immunohematology, 2014, 30(4): 161-5.
[11] Ji Y, Wen J, Veldhuisen B, et al. Validation of the multiplex ligation-dependent probe amplification assay and its application on the distribution study of the major alleles of 17 blood group systems in Chinese donors from Guangzhou. Transfusion, 2017, 57(2): 423-32.

[12] Nichols JH. Verification of method performance for clinical laboratories. Adv Clin Chem, 2009, 47: 121-37.

(Received 24 April 2019, Revised 24 May 2019, Accepted 01 June 2019) 


\section{Features}

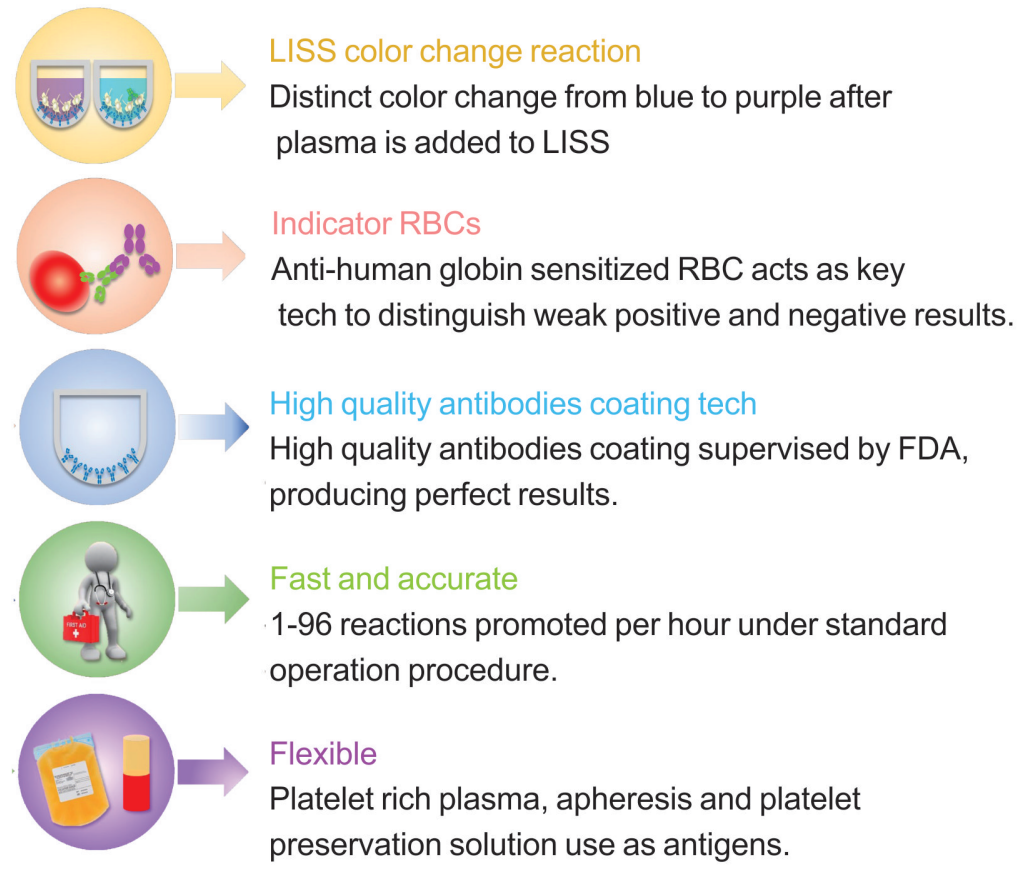

\section{Package}
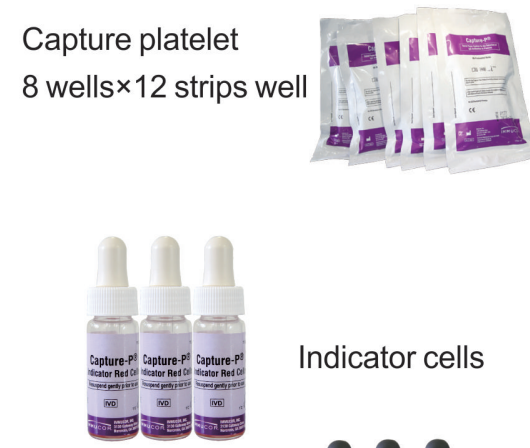

LISS

Indicator cells
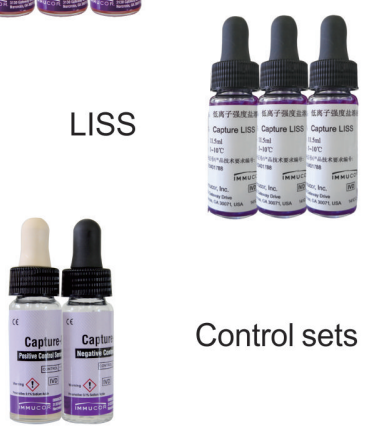

Control sets

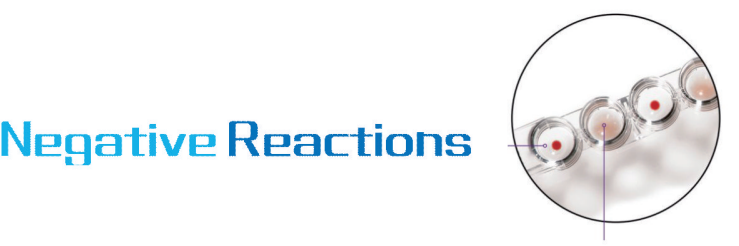

Positive Reactions

Antibody screening can be conducted to prevent

the Ab-Ag complex induced.........

\section{Cross match}

Cross match can make sure apheresis is transfused

to patients appropriately.

Pregnant screening

HPA Abs can induce recurrent abortion easily as compared to Abs negative ( $R R=7.5)$
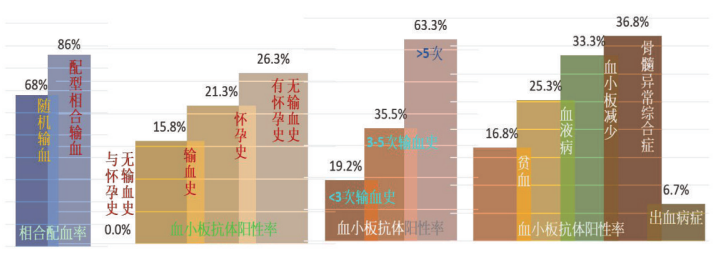

zolduni JiangSu ZoJiWat Bio-pharmaceutical Co., Ltd.

Address: No. 78 West Dongsheng Road, Jiangyin, Sales : 15370255367 Jiangsu214400, P,R.China Mail:3246683473@qq.com

Tel: 0510-81695399, 81695092

Fax: 0510-81695129

Web site: www.jszojiwat.com

Technical services: 15190368370

Mail: caochen0910@163.com

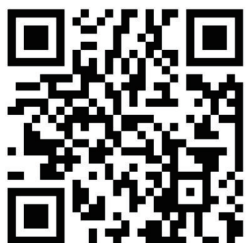

